\title{
Queimar e postar: materializar arquivos imateriais
}

\author{
Grupo de Pesquisa em Processos de Criação ${ }^{1}$
}

Introdução

A chama determina a acentuação do prazer de ver, algo além do sempre visto. Ela nos força a olhar.

Gaston Bachelard ${ }^{2}$

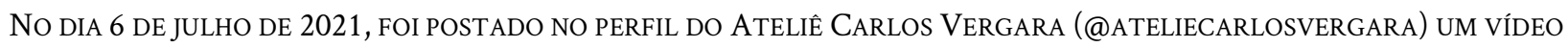
com a queima de um quadro do artista. Ele havia registrado o processo de criação dessa mesma obra em outro vídeo e postado no reel anterior, de 25 de junho de 2021, conforme veremos a seguir.

A postagem e o registro da queima de um arquivo, para aqueles que se dedicam a estudar os processos de criação, a princípio, geram um certo desconforto. Esta reação levou-nos a partilhar o post de Vergara com o Grupo de Pesquisa em Processos de Criação da PUC-SP no WhatsApp. A pergunta “o que estamos vendo?” e a constatação de que foi feita uma escolha: tornar público o percurso de produção do quadro, queimar, filmar e postar ficou evidente. E, ao mesmo tempo, ali estava um novo registro de processo, agora, de destruição da obra, gerando nova documentação em seu arquivo de criação.

Carlos Vergara é um artista brasileiro com extensa e importante trajetória, com mais de 180 exposições individuais e coletivas. Participou tanto de eventos nacionais, como a Bienal de Arte de São Paulo e o Salão de Arte Moderna do Rio de Janeiro, como internacionais, apresentando seu trabalho na Bienal de Veneza e Bienal de Medellín. Tem parcerias com outros relevantes artistas, como Hélio Oiticica, Waltercio Caldas e Caetano Veloso.

Vergara é um artista de múltiplas linguagens. Suas obras combinam diversos materiais, técnicas e plataformas de exibição. Já expôs quadros, gravuras, fez cenários para peças de teatro e produziu fotografias e filmes. O relacionamento do artista com o audiovisual não é recente. Na década de 70, quando o foco de seus trabalhos era o carnaval brasileiro, Vergara utilizava as câmeras Super-8, mais leves e portáteis, para registrar o Bloco Cacique de Ramos. E, em 1985, codirige o vídeo experimental "Uma pintura” com Belisário França e Piero Mancini, em que registra o processo de criação de um quadro, demonstrando as questões, dúvidas e apostas para a confecção da tela.

É possível destacar, portanto, que o registro audiovisual dos arquivos da criação, tanto os que foram descartados como os que são incorporados aos seus trabalhos, não é algo novo para Vergara. As performances de processo não surgiram apenas agora com a difusão de vídeos para redes sociais. A postagem no Instagram, porém, trouxe um aspecto novo, o artista não só descarta o material, mas queima-os, filma e posta (Figura 1 e 2).

\footnotetext{
${ }^{1}$ Artigo escrito pelos investigadores Cecilia Salles, Júlia Meireles, Mariana Carlin, Paola Pinheiro, Patrícia Dourado, Samir Cheida e Vinícius Gonçalves, do Grupo de Pesquisa em Processos de Criação. Fundado em 1993, o grupo tem sede no Programa de Comunicação e Semiótica da PUC-SP e faz parte do diretório de grupos do CNPq, atuando intensamente na área dos estudos dos processos de criação em diferentes áreas (artes visuais, cinema, literatura, teatro, dança, fotografia etc.). Para saber mais, visite: https://processosdecriacao.com.br/
}

${ }^{2}$ A chama de uma vela, 1989, p. 11.

${ }^{3}$ Disponível em: <https://www.youtube.com/watch?v=DFVWKYx5ZX0>. Acesso em: 29, jul. 2021. 

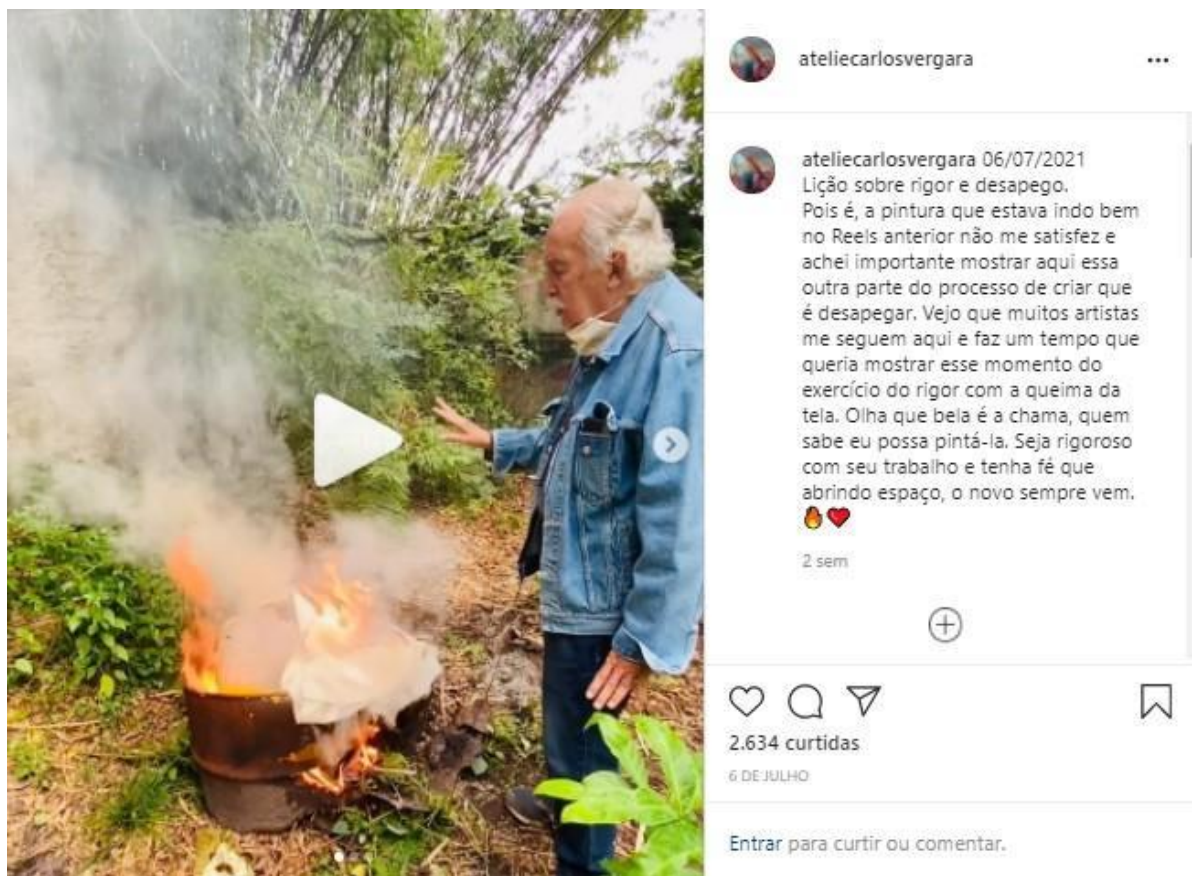

Fig. 1. Postagem do dia 6 de julho de 2021, com o registro em vídeo da queima do quadro cujo trabalho foi registrado no reel anterior. Screenshot realizado pelos autores. ${ }^{4}$

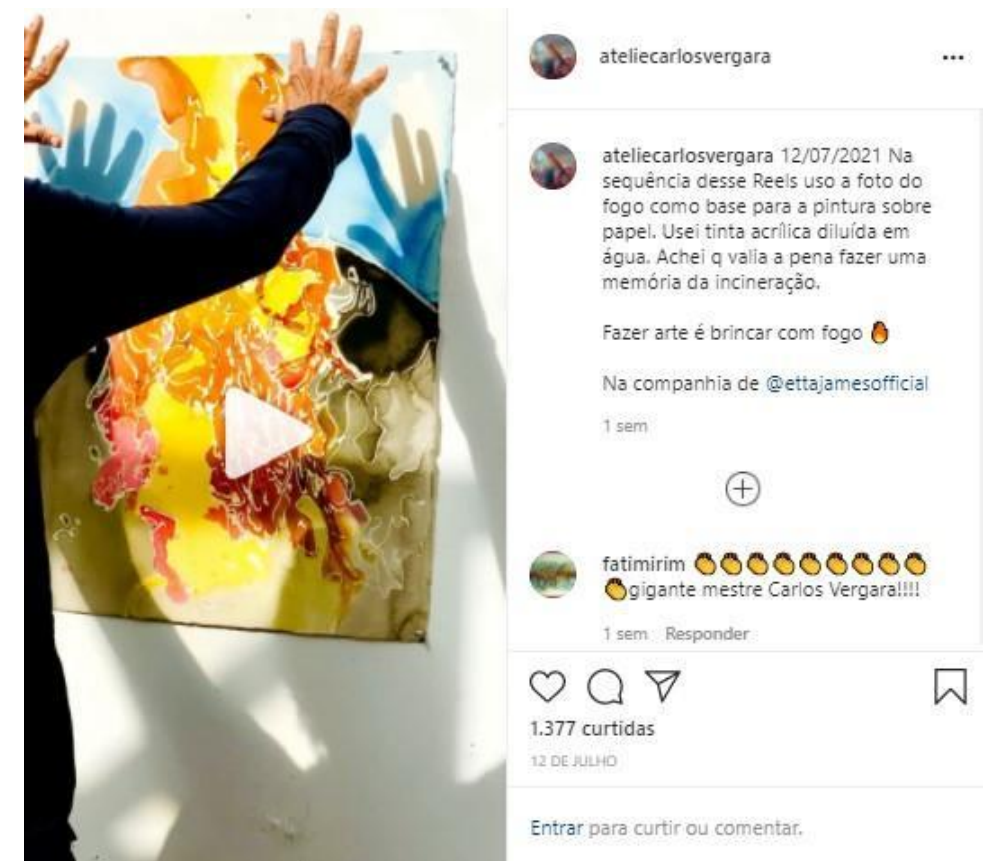

Fig. 2. Postagem do dia 12 de julho de 2021, com o registro da criação do novo quadro que tem por base a queima do quadro anterior. Screenshot realizado pelos autores. ${ }^{5}$

${ }^{4}$ Instagram do artista: <https://www.instagram.com/p/CQ_HtGcpkuj>. Acesso em: 29, jul. 2021.

${ }^{5}$ Instagram do artista: <https://www.instagram.com/reel/CRPJslhpVpo >. Acesso em: 29, jul. 2021. 
É conhecido o pedido do escritor Franz Kafka, deixado em carta ao amigo Max Brod, para queimar todos os seus manuscritos, esboços, diários e cartas sem os ler, diante da morte iminente em Viena. Ele estava longe do escritório em Praga, onde estava a maior parte dos seus escritos. O amigo e primeiro biógrafo do escritor aponta que Kafka queimou em vida possivelmente $90 \%$ de sua obra e que o pedido de queimar sem ler foi feito à pessoa errada. Max Brod amava cada palavra que Kafka escrevia e era quase certo que não cumpriria o pedido.

O que a prática da queima recorrente dos arquivos nos conta sobre o processo de criação, por exemplo, de Kafka, que costumava passar a maior parte do tempo a editar e reescrever? Se houvesse câmeras portáteis e redes sociais à época de Kafka, será que alguma das queimas teriam sido registradas e postadas? Ele talvez fizesse, à semelhança de Vergara, uma performance do seu rigor? Talvez o próprio Max Brod documentasse o processo? Tentativas de aproximação entre práticas semelhantes, mas distintas no tempo.

Não é de hoje que diversas práticas imateriais são registradas por diferentes materialidades, como o relato de um processo a que só temos acesso por meio desse relato (escrito ou gravado), contido em entrevistas, diários e mesmo em livros. O audiovisual e a internet alargaram ainda mais este universo de possibilidades de arquivamento de processos em diferentes materialidades. E, ao mesmo tempo, a contemporaneidade e as ferramentas de registro que acumulamos (analógicas e digitais) têm gerado, também, novas relações entre as obras, os processos e as formas de tornar público.

O que as imaterialidades que moram nas materialidades da criação têm a nos contar sobre o processo dos diferentes artistas e sobre os processos de criação em geral? E quais têm sido as contribuições das materialidades digitais nesse caminho? São algumas das perguntas que nortearam a escrita deste artigo.

Escolhemos, para efeito de condução das questões levantadas, dividir o artigo em três partes. Na primeira, analisamos o acúmulo e a convivência entre diferentes práticas de arquivamento, como as publicações de Anna Maria Maiolino. Trazemos, também, outros exemplos de queima de arquivos, como o projeto Fogo (2017-2018) de Luca Benites e o projeto The Burned Picasso (2021) do coletivo Fractal. Na segunda parte, tratamos especificamente sobre o processo de queima, registro e postagem de Carlos Vergara, especialmente na relação entre performance e registro audiovisual. E, na terceira e última parte, analisamos o contexto de arquivamento digital de processos de criação que redes como o Instagram têm oferecido.

\section{Acúmulo e convivência entre as práticas de arquivo}

Diante da proposta de discutir os arquivos imateriais, mais especificamente, os desafios da criação no contexto digital, o queimar e postar de Vergara nos colocou uma questão de extrema relevância para as reflexões que nos guiam aqui. Estamos partindo desse projeto, no entanto, a experimentação artística na interação com as mídias sociais, no contexto da pandemia (mas não só) tem colocado o arquivo contemporâneo em estado de permanente instabilidade.

Vergara explora de modo bastante instigante e diverso as materialidades digitais dos arquivos. Ao mesmo tempo, estamos diante de um recurso bastante recorrente na experimentação contemporânea, que é a mediação do audiovisual como modo de dar materialidade e tornar público os arquivos da criação. Arquivos saem de modo definitivo dos bastidores (visão tão cara à Crítica Genética francesa) e passam a se tornar obras, na interação com a performance.

Assistimos, no caso de Vergara, à edição do processo de criação analógico de um quadro. Em todos os percursos, há o enfrentamento de erros que geram ajustes, adequações ou cortes que, no caso da pintura, podem se concretizar sob a forma de telas rejeitadas, abandonadas ou eliminadas. Neste caso, tudo isso é filmado, editado e tornado público. O artista mesmo adverte na publicação anterior à queima (Figura 3): "Quando concluir, se der certo, mostro aqui o resultado" (@ateliecarlosvergara, 25 de junho de 2021), explicitando um dos aspectos comunicativos dos processos: a ação de tornar a obra pública. 


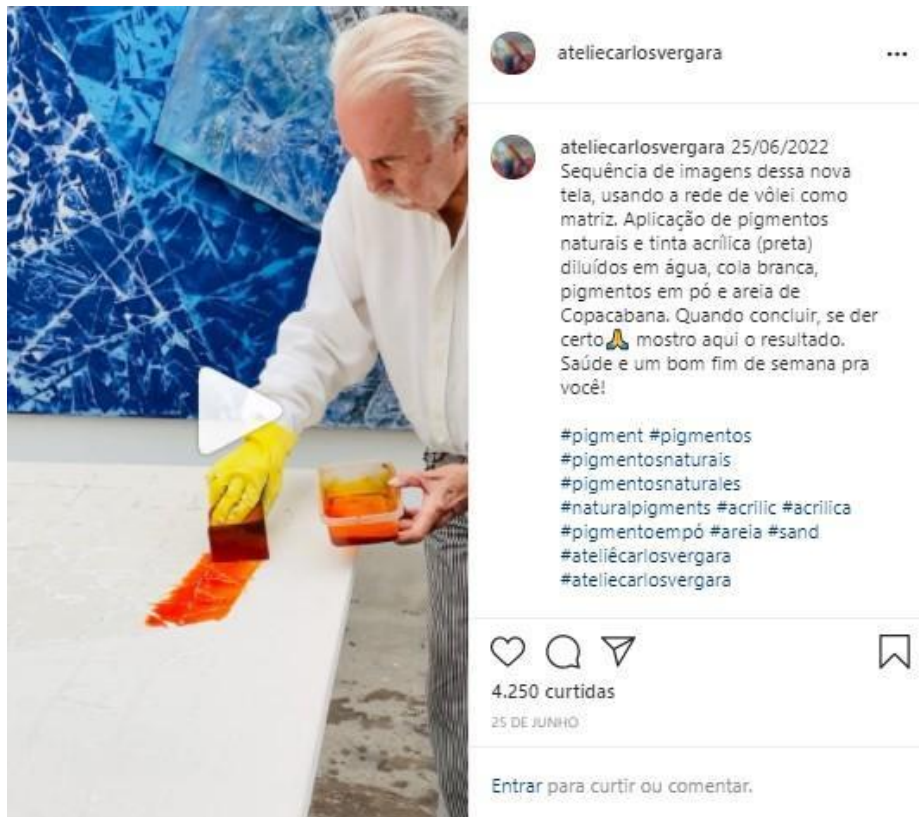

Fig. 3. Postagem do dia 25 de junho de 2021, com registro da criação do novo quadro. Screenshot realizado pelos autores. ${ }^{6}$

Acreditamos que os desafios, na verdade, são colocados para a crítica. Em outras palavras, o artista coloca as questões, e cabe à crítica encontrar instrumentos teóricos para discuti-las. Em nosso contexto, trabalhar a expansão da crítica genética é inevitável para até podermos perceber que uma ação como a de Vergara diz respeito a nós, pesquisadores de processos de criação. Atuações como essas colocam explorações dos arquivos da criação para além de qualquer tentativa de definir fronteiras entre processo e obra, público e privado.

Há também a necessidade de tornar o processo de criação público que, nesse caso, se dá na interação analógico e digital. Quando acompanhamos o processo de diferentes artistas, percebemos que essa é uma prática recorrente na experimentação contemporânea.

Como outro exemplo, podemos citar a artista ítalo-brasileira Anna Maria Maiolino ${ }^{7}$, que escolhe divulgar os diversos documentos de seu processo especialmente em livros, portfólios e catálogos de arte. Lembramos que muitos outros artistas usaram esse mesmo recurso analógico de Maiolino. Agora estamos falando do uso (a mais) das redes sociais, o que nos faz destacar o acúmulo e a convivência entre as práticas de registrar e de tornar público. Em todos os casos, o importante é que tudo é feito por necessidade dos artistas.

As publicações de Maiolino são materiais instigantes para o pesquisador interessado nos processos de criação, pois tornam pública uma variedade de registros dos bastidores como esboços, maquetes, croquis, fotografias, rascunhos etc. No catálogo Anna Maria Maiolino (2012), organizado pela curadora Helena Tatay, encontramos, por exemplo, um esboço de um projeto de uma instalação realizada para o Museu do Açude (Figura 4), no Rio de Janeiro, em 1999.

\footnotetext{
${ }^{6}$ Instagram do artista: <https://www.instagram.com/p/CQjDIulJakj/> Acesso em: 29, jul. 2021.

${ }^{7}$ Anna Maria Maiolino nasceu em 1942, em Scalea, na Calábria, sul da Itália. Chega ao Brasil na década de 1960 e naturalizase em 1968. Maiolino investiga diversas linguagens da arte, como xilogravura, fotografia, vídeo, instalação, performance, desenho, pintura, escultura etc. Na década de 60, integrou o movimento Nova Figuração e participou da exposição Nova Objetividade Brasileira (1967) (MAM/RJ).
} 


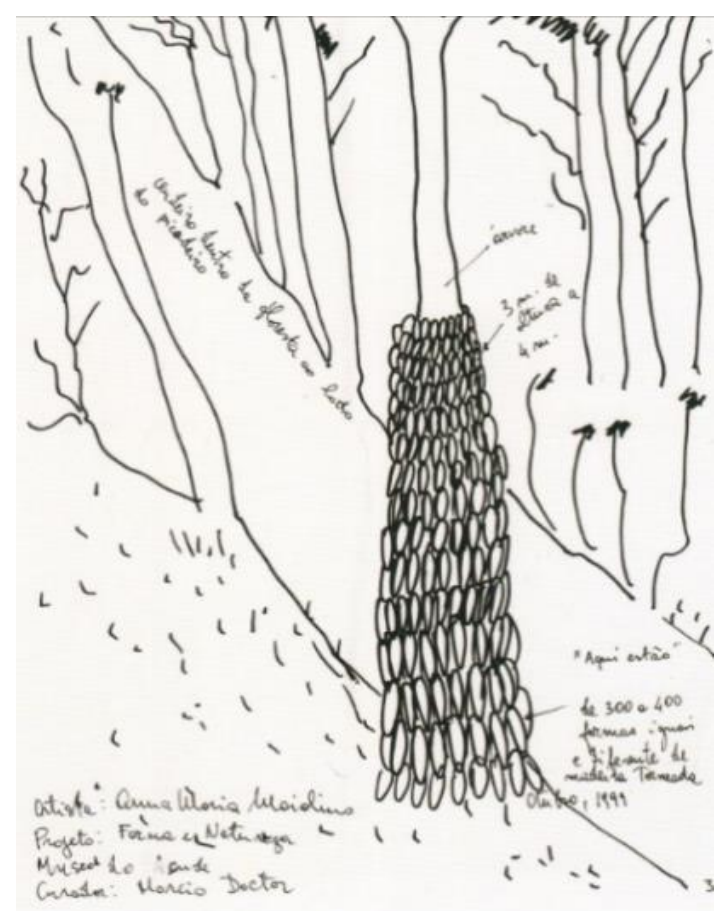

Fig. 4. Esboço de instalação permanente, projeto A Forma na Floresta, Museu do Açude, 1999. Exemplo de registro de processo da artista Anna Maria Maiolino, no catálogo Anna Maria Maiolino (2012), organizado pela curadora Helena Tatay. ${ }^{8}$

Esses documentos, além de revelarem as diversas hipóteses que são levantadas ao longo do processo de criação, também demonstram a importância que os artistas conferem aos processos e aos seus registros. Isso é reforçado nas opções editoriais de tais publicações, que colocam em evidência o processo de criação e o interesse da artista em tornar público esses registros.

Esse aspecto se torna ainda mais evidente quando Suely Rolnik ${ }^{9}$ diz: "uma característica marcante para Maiolino consistiu em enfatizar a experiência que se dá no processo artístico e deixar de restringir a investigação a seu produto, objeto”. Essa necessidade de Maiolino está estreitamente ligada à relevância que a artista dá a seu processo de criação, também enfatizada por sua própria fala: "interessam-me os processos do trabalho, a preparação, o que antecede a obra terminada"10.

No exemplo de Vergara, vemos a utilização das mídias sociais como (mais um) meio de divulgação do seu próprio processo e (mais um) espaço potencializador de interações entre o processo, as obras e o público.

Além dos meios em que esses registros tomam materialidade, junto a isso, outros pontos são importantes de destacar: a evidente necessidade de registro, de tornar esse registro público e o desejo de gerar memória, também, na destruição - de gerar algo da luz do fogo da incineração.

O queimar e registrar, neste caso, gera um rastro público e digital, um vestígio do processo do artista. A fumaça que indicia o fogo, ao mesmo tempo e, paradoxalmente, indicia, também, caminhos e escolhas do próprio processo de criação de Vergara: "tem que ter rigor”; "não pode ter apego só porque você fez" (@ateliecarlosvergara, 6 de julho de 2021).

A fumaça registrada e postada indicia, também, o desejo de gerar memória de um ato que seria de apagamento - se não fosse um ato, também, de transformação. Como na antiga prática da agricultura de queimar o resto da antiga plantação para, do insumo da cinza, gerar a próxima colheita.

\footnotetext{
${ }^{8}$ Maiolino, A. M. In: TAtay, H., 2012.

${ }^{9}$ ROLNIK, 2002, p. XVII.

${ }^{10}$ Maiolino, 2012, p. 53.
} 
A relação entre queima/morte e criação/vida é uma figura recorrente, e artistas como Luca Benites ${ }^{11}$, por exemplo, foram ao extremo com ela. Benites, à semelhança de Vergara, fez do gesto e da matéria da queima o ponto de virada de um processo; neste caso, o de uma obra inteira. $\mathrm{O}$ artista queimou todas as suas obras acumuladas ao longo de 18 anos, e cuja queima virou um livro, um documentário e outras obras a partir das cinzas. Em 2017, Benites deu andamento ao que chamou de projeto Fogo (Figura 5), ideia que apareceu pela primeira vez em anotações de um caderno em 2015 (Figura 6). A ideia amadureceu, ouviu, e continua a ouvir, muitas críticas.
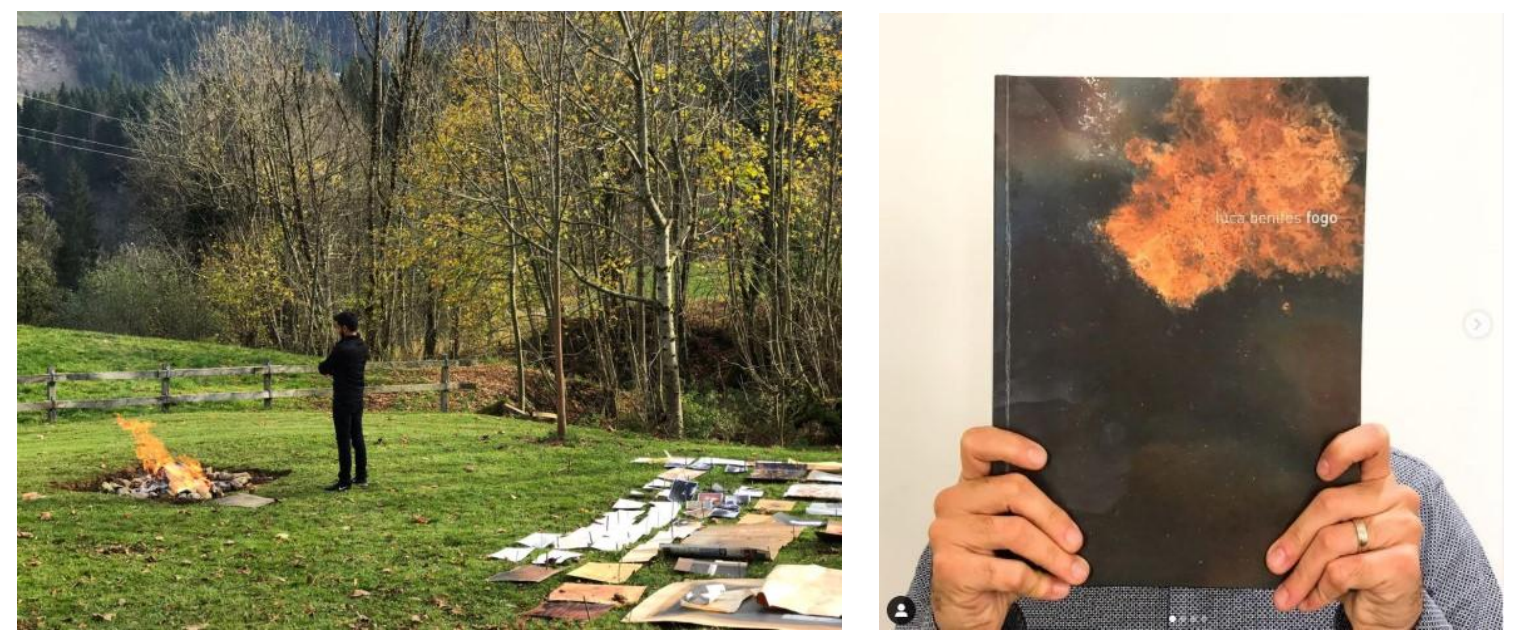

Fig. 5 e 6. À esquerda, o registro em livro do projeto Fogo (2017-2018) de Luca Benites, em que o artista queimou 300 obras e transformou o processo da queima em documentário, livro e matéria (a cinza) para outras obras, entre elas Relógio de cinzas (2017-2020), Pintura com cinzas (2017-2020), Gota a gota (2018) e Meu tempo em minhas mãos (2018). ${ }^{12}$ À direita, o registro do livro Fogo no perfil do artista no Instagram. Screenshot realizado pelos autores. ${ }^{13}$

Mais uma vez, a nossa indagação: por que queimar? Para Vergara, era o "rigor", "não estava bom”. Para Benites, queimar todas as suas obras, ir atrás de cada uma onde estavam expostas em diferentes galerias e museus do mundo, e queimá-las, uma a uma, foi uma forma de destacar, segundo ele, que "o importante tinha sido o tempo" dedicado ao gesto de fazer cada obra, e que isso, para ele, "era mais valioso que a obra em si”. A reflexão sobre como o tempo havia sido "queimado" nos últimos 18 anos era mais importante, e o registro desta queima era um modo de materializar esta questão: de que estamos sempre a queimar o tempo, a transformá-lo em chama, de uma forma ou de outra.

Quanto é apagado, editado, curado tantas vezes nos processos de criação das diversas artes, nos espaços privados dos ateliês, escritórios, salas de ensaio e ilhas de montagem? Vergara e Benites tornaram também esse processo público e fizeram dele outras obras.

\footnotetext{
${ }^{11}$ Artista visual brasileiro, formado em arquitetura no Uruguai, onde viveu por mais de 15 anos. Nasceu em Brasília, em 1981, e atualmente vive em Barcelona. Suas obras já integraram mais de 70 exposições internacionais em várias cidades do mundo. Em 2017, seu trabalho ganhou ainda mais notoriedade com o projeto Fogo, em que queimou todo seu acervo produzido ao longo de 18 anos e o transformou em livro, documentário e outras obras, tendo a cinza como matéria. Hoje é o mais jovem expositor da Dan Galeria (São Paulo, Londres, Portugal).

${ }^{12}$ Site oficial do artista: <http://lucabenites.com >. Acesso em: 29, jul. 2021.

${ }^{13}$ Instagram do artista: <https://www.instagram.com/p/BqyChhwg0AO/>. Acesso em: 29, jul. 2021.
} 
O coletivo Fractal $^{14}$, por sua vez, diferente de Vergara e Benites, que queimaram as suas próprias obras, decidiram, por meio do projeto The Burned Picasso (2021), alargar a questão do arquivamento, também, das obras, por meio da transformação do rascunho Fumeur V (1964) de Pablo Picasso (Figura 7) em uma obra digital encriptada, um NFT (Non Fungible Token), como um modo de alargar o universo de materialidades do contexto digital para obras originais e arquivos. Segundo Pandu Sastrowardoyo, curador e porta-voz da Fractal, no universo da encriptação digital e do blockchain, a "destruição criativa" (Figura 8) é, também, segundo o grupo, uma forma de eternizar uma peça física e de questionar o que é real.
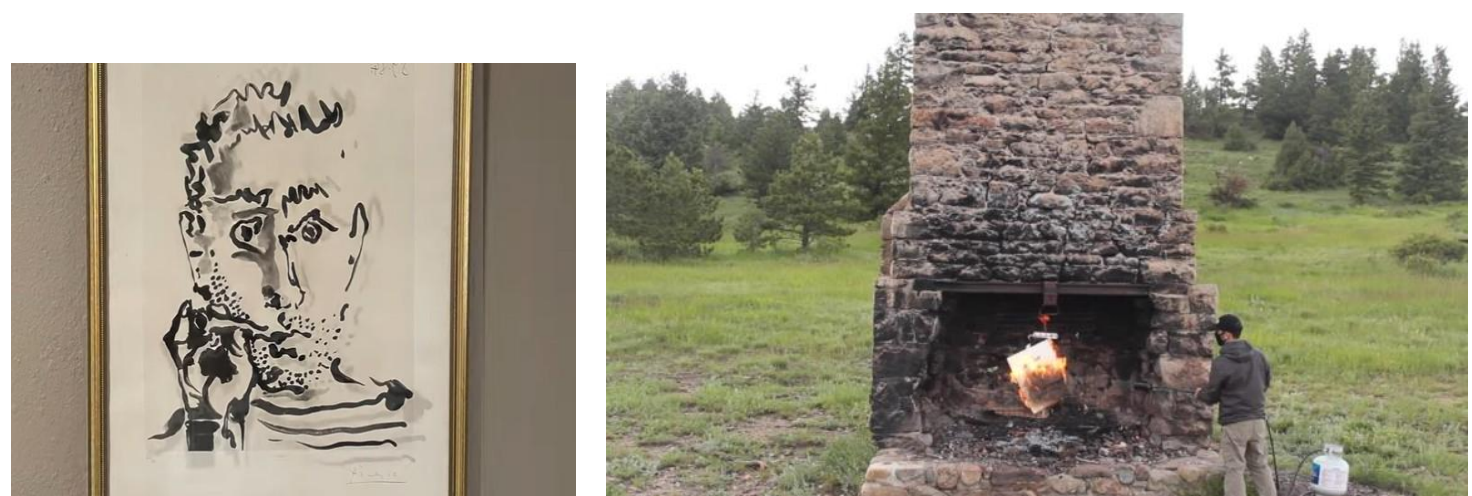

Fig. 7 e 8. À esquerda, o rascunho de Pablo Picasso que foi comprado, queimado pelo grupo e transformado em NFT (Non Fungible Token) pelo grupo. ${ }^{15}$ À direita, o registro da queima do rascunho, cuja ação foi filmada e tornada pública. ${ }^{16}$

É possível perceber nesses processos a queima associada ao desejo de gerar registro a partir da chama. Aqui lembramos Gaston Bachelard, cuja epígrafe abre este artigo, e que destaca o poder de fazer ver que a chama traz: "A chama determina a acentuação do prazer de ver, algo além do sempre visto. Ela nos força a olhar" ${ }^{\text {17 }}$. Nos três processos de queima citados (Vergara, Benites e Fractal), a performance (a provocação do olhar, o convite a olhar de novo) e o registro audiovisual compartilhado configuraram elementos-chave da partilha do processo.

\section{Performance de arquivo e registro andiovisual}

Neste tópico, discutiremos, de modo mais aprofundado, o processo de Vergara, especialmente na relação entre performance e registro audiovisual. João Vergara, seu filho, é responsável pela montagem, pela curadoria de arquivo para o Instagram e pela gestão do Arquivo e do Ateliê Carlos Vergara. Sem nos aprofundar nessa questão, destacamos a impossibilidade de falarmos em processos eminentemente individuais.

Tomamos aqui o processo de queima do quadro de Vergara como uma performance diante da avaliação do artista que aquela obra produzida no vídeo anterior não deveria ser mostrada publicamente, gerando uma nova obra: a pintura sobre o

\footnotetext{
${ }^{14}$ Coletivo de artistas independentes, com sede no RiNo Art District, em Denver. O trabalho com o Metaverso e a transformação de materiais para o universo digital do blockchain (cadeia de blocos de alta encriptação, do qual fazem parte, por exemplo, os bitcoins) tem sido uma das áreas de atuação do grupo. Eles propõem que "mover aspectos de nossa vida do mundo in-world para a Web3.0 não os destrói, mas os transforma” (site do projeto The Burned Picasso).

${ }^{15}$ Site oficial do projeto The Burned Picasso: <https://uniqueone.medium.com/picasso-enters-the-metaverse-f1cc48c77ed8>

> Acesso em: 29 jul. 2021.

${ }^{16}$ Ibidem.

${ }^{17}$ BACHELARD, 1989, p. 11.
}

Queimar e postar: materializar arquivos imateriais 
ato da queima. Assim, o artista comenta a sua ação: "faz um tempo que queria mostrar esse momento do exercício do rigor com a queima da tela. Olha que bela é a chama, quem sabe eu possa pintá-la” (@ateliecarlosvergara, 6 de julho de 2021) (Figura 1). Não podemos deixar de destacar que é um gesto movido, também, pela sedução que o fogo exerce nele, ou seja, os efeitos sensíveis que agem sobre os artistas ao longo de todos os processos.

O performer também atua como observador, como todos os artistas em seus processos. Ele observa sua própria produção, ocupando o duplo papel de protagonista e receptor. Na performance da queima de arquivos, o artista observa e critica sua própria obra, e foi o fato de observá-la que o conduziu ao desejo de queimar e de performar a queima, em um exercício performático do rigor: "achei importante mostrar aqui essa outra parte do processo de criar que é desapegar. Vejo que muitos artistas me seguem aqui” (@ateliecarlosvergara, 6 de julho de 2021).

A ação do performer produz novos significados para sua arte e, ao mesmo tempo, é reveladora dos seus processos: uma performance de processo. Queima-se o arquivo, mas, dele, novos nós de interação são gerados e novos índices são suscitados. A performance é o convite a ver de novo, a ver melhor. Neste caso, também ver de novo, rever, algumas questões da própria arte, como o apego na hora do corte, da borracha, do delete, do fogo... de que Vergara fala, "não dá para trabalhar sem desapego” (@ateliecarlosvergara, 6 de julho de 2021).

Só é possível falar em "desapego" porque há também o "apego", e o registro audiovisual da queima, da aparente "destruição", associado à performance, enfatiza a continuidade do desejo de criar algo da chama, do fogo. A relação apego/desapego não é um paradoxo superado, pelo contrário, é mais uma propulsora do processo. Não por acaso, "as performances realizam uma crítica às situações de vida: a impostura dos dramas convencionais, o jogo de espelhos que envolve nossas atitudes e sobretudo a natureza estereotipada de nossos hábitos e ações ${ }^{\prime 18}$. O artista, com a queima do arquivo registrada e publicada, nos convida a refletir sobre a própria noção de arquivo e de apego/desapego, ao colocar em crise os hábitos, a duração e a ideia de valor material e de conservação às cegas (são suficientes?).

$\mathrm{O}$ artista performa e observa a sua prática na ação da queima registrada, como um arquivo de si mesmo. A prática, como fonte dos índices do processo de criação, é, neste caso, tão reveladora sobre o processo de Vergara como talvez fosse o arquivo queimado em si. Os arquivos são vastos e se acumulam.

$\mathrm{O}$ ato de queimar é, aqui, o arquivo, e este ato está carregado de muitas nuances para aqueles interessados no estudo dos processos de criação. Se o ato (imaterial) é o arquivo, essa imaterialidade encontra outros meios, e materiais, pelos quais se expressar: a performance registrada é uma delas. $\mathrm{O}$ audiovisual tem sido um importante documentador de muitos gestos imateriais que encontram, na materialidade audiovisual, meios de durar e de ir ao encontro dos seus observadores.

É importante, por isso, destacar ainda algumas especificidades do modo como o artista se vale da linguagem audiovisual para registrar a performance da queima de arquivo e transformar o processo de criação em uma nova obra. A queima do material é registrada e é convertida em material bruto para ser retrabalhado na edição audiovisual. Ao justapor as imagens dos arquivos descartados, o montador ressignificou os arquivos, utilizando conceitos de montagem (Kuleshov) para mostrar como isso se transformou em ideia para uma nova pintura.

Em um primeiro momento (Figura 1), temos, no vídeo, Vergara diante de um tambor que queima papelões e faz uma fumaça preta. Ele justifica o ato de queimar como um ato de rigor, "se não está bom, deve ser jogado fora”. Nessa postagem, a câmera se aproxima da linguagem de documentário, procurando apenas registrar o momento da queima do material.

Já na postagem seguinte (Figura 2), há um processo de montagem audiovisual mais sofisticado. O registro da queima do material se torna um videoclipe, com a música "Fire" de Etta James como trilha sonora para o novo vídeo do Instagram. O artista inclusive utiliza elementos da linguagem do videoclipe, como a câmera lenta na primeira imagem do fogo, a imagem congelada, cortes na batida da música e alguns zoom in (aproximação da lente da câmera) que seguem o ritmo da trilha sonora.

${ }^{18}$ GLUSBERG, 2013, p. 72. 
Compiladas, as imagens constroem a ideia de que a partir do fogo, da queima, Vergara aproveitou os movimentos e as tonalidades do fogo para produzir o novo quadro.

As imagens sozinhas não carregam essa ideia, de que o desfazer dos rascunhos se converteu em nova ideia dentro do processo de criação do artista. O próprio artista se valeu da linguagem audiovisual e da montagem para construir esse sentido. O montador dialoga com as teorias dos cineastas russos Eisenstein e Kuleshov que demonstram que imagens e sons podem ser retirados do seu contexto original e manipulados para novos direcionamentos. Portanto, além de mediar e tornar público os arquivos da criação, o audiovisual também imprime sua linguagem e, combinando novos elementos, reforça o conceito de que processo é obra ${ }^{19}$ e converte os arquivos da criação em mais um objeto para apreciação e que pode ser pesquisado.

É importante também observar que os dois vídeos têm características de linguagem da mídia onde vão ser veiculados. O Instagram utiliza a janela vertical, na proporção 9/16, e limita as postagens em trinta segundos por vídeo nos reels. O artista completa sua fala e sua ideia no tempo imposto pela rede social, demonstrando consciência de onde está publicando os seus registros.

\section{0 arquivo digital Instagram e a rede compartilhada}

A possibilidade de rompimento das barreiras do tempo e do espaço inaugurada pela interação em ambientes digitais parece sugerir novos caminhos de experimentação artística, bem como o compartilhamento, proposital ou não, de arquivos da criação. Com o potencial colaborativo das redes sociais digitais, o arquivamento de ideias tende a se tornar uma experiência compartilhada, dinâmica e coletiva. Essa qualidade amplia o horizonte criativo e acrescenta nuances ao trabalho do artista, na medida em que possibilita a verificação quase imediata de algumas respostas do público, permite reformulações em meio ao processo criativo e impõe condições imprevistas às experimentações.

Essa característica manifesta, ainda que de forma imaterial, o que Vincent Colapietro designou por pluralidade dos locais da criatividade, que consistem nos lugares onde diversas práticas se interceptam, ou seja, os caminhos que o artista percorre para desenvolver seu projeto. Esse caminho constitui o diálogo entre o agente criativo, os materiais com que trabalha, as tradições que o cercam e, nesse espectro específico do ambiente digital, as influências decorrentes dos recursos e da resposta das redes sociais.

É, sobretudo, um processo no qual a seleção é geradora de possibilidades. Isto é, a seleção não é apenas ou principalmente um processo de eliminação. A seleção é, em alguns aspectos cruciais, geradora, abrindo ou expandindo um campo de possibilidades, ao invés de limitar ou destruir esses campos. $^{20}$

A utilização das redes sociais digitais por artistas propõe, assim, a investigação da poiesis como um processo de geração, em que cada fase é simultaneamente gerada e geradora. Dessa forma, qualquer etapa é tanto resultado como origem, ou seja, a soma de um passado real e a abertura de futuros possíveis ${ }^{21}$.

Quando voltamos nosso olhar para as postagens em redes como o Instagram, há de se levar em conta que a própria lógica de compartilhamento da rede rege certas escolhas estéticas de publicação de arquivos, obras e processos. Elas podem tanto moldar-se às ferramentas proporcionadas pela plataforma, como podem nascer do modelo de compartilhamento on-line, suscitando a criação de materiais de arquivo para serem divulgados coletivamente.

\footnotetext{
${ }^{19}$ SALLES, 2006.

${ }^{20}$ Colapietro, 2010, p. 18.

${ }^{21}$ Colapietro, 2010.
}

Queimar e postar: materializar arquivos imateriais 
No caso da sequência de postagens do artista Carlos Vergara, entramos em contato com diversas etapas do processo que são compartilhadas de formas diferentes e em momentos distintos. $\mathrm{O}$ artista se utiliza da ferramenta reels para divulgar o processo de criação de sua tela - enfatizando a data do registro audiovisual, bem como a montagem e o tempo pré-estabelecido pela lógica operacional da plataforma.

Dias depois, entramos em contato com o que o artista chama de "Lição sobre rigor e desapego" (@ateliecarlosvergara, 6 de julho de 2021). Nela, Vergara documenta o próprio desapego em relação ao seu trabalho e utiliza a rede social como forma de compartilhamento desse ritual presente na esfera criativa de diversos artistas - o queimar da obra, sua desmaterialização.

O que fica claro, mais adiante na descrição de sua postagem, é o desejo do artista em mostrar "esse momento do exercício do rigor com a queima da tela” (@ateliecarlosvergara, 6 de julho de 2021) - fazendo com que esse registro de arquivo de criação resguarde, a princípio, duas camadas de sentido.

A primeira delas, se refere ao seu âmbito performático - de queimar a tela enquanto símbolo contrário ao rigor e a favor do desapego como parte do processo. A segunda, em relação a documentação do arquivo, que nasce do desejo de compartilhamento em rede para que o próprio inacabamento de sua obra seja documentado e se torne, também, um arquivo de (re)criação, quando divulgado na plataforma interativa. O inacabamento, elemento-chave do conceito de processo de criação, parece ganhar um novo meio de exposição, a partir desse arranjo de materiais artísticos realizado por Vergara.

Esse inacabamento dos processos de criação documentados por meio das redes digitais é revelador da incerteza de resultados que acompanha a criação. $\mathrm{O}$ artista habita o universo da mutabilidade, imprevisão e incerteza. Esse universo, quando alocado no contexto de plataformas on-line, parece se expandir ainda mais, e carrega consigo potências de experimentação do artista em relação à obra, ao processo, aos arquivos e ao público.

\section{Conclusão}

Chegamos ao fim de nossas reflexões dando destaque ao modo de produção deste artigo. Trata-se de uma experimentação no contexto acadêmico, gerada por necessidade do Grupo de Pesquisa em Processos de Criação da PUC-SP. Optamos por ultrapassar o limite de autores determinado pelas normas de periódicos. Cada um de nós entrou com a especialidade de seu olhar que, por sua vez, está ligada às pesquisas por nós desenvolvidas de modo um pouco mais individual. Fomos movidos pelo desafio da postagem do processo de Vergara em nosso grupo de WhatsApp e voltamos, assim, às redes sociais e aos seus potenciais de interação e criação de novas possibilidades.

No exemplo de Vergara, Instagram, audiovisual, arquivos (editados) e postados queimam como uma rasura performatizada, processo como obra, ou seja, o desafio colocado pelo artista obriga os pesquisadores de processo de criação a saírem em busca de uma crítica de processos, a inevitável expansão da crítica genética mencionada no começo deste artigo.

\section{Referências}

BACHELARD, G. A chama de uma vela. Rio de Janeiro: Bertrand Brasil, 1989.

BENITES, L. Entrevista. In: A vida é uma arte. Porto Alegre: ABF Developments, 2021. Disponível em: <https://fb.watch/72ivBexkw3/>. Acesso em: 29, jul. 2021.

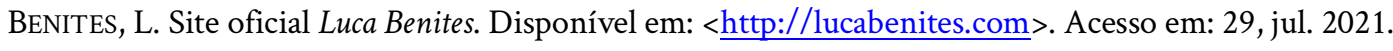

BROD, M. Franz Kafka: a biography. Boston: Da Capo Press, 1995. 
revista de crítica genética

Colapietro, V. The loci of creativity: fissured selves, interwoven practices. Manuscrítica revista de crítica genética 11. São Paulo: Annablume, 2003.

EISENSTEIN, S. A forma do filme. Rio de Janeiro: Jorge Zahar, 2002.

Glusberg, J. A arte da performance. São Paulo: Perspectiva, 2013.

Maiolino, A. M. In: Tatay, H. (Org.). Anna Maria Maiolino. São Paulo: Cosac Naify, 2012.

SAlles, C. A. Arquivos de criação: arte e curadoria. Vinhedo: Editora Horizonte, 2010.

Redes da criação: construção da obra de arte. Vinhedo: Editora Horizonte, 2006.

ROLNIK, S. Flowerings of reality / florações da realidade. In: ZEGHER, C. de (Ed.). Anna Maria Maiolino: a life line / vida afora. New York: The Drawing Center, 2002. p. XVI-XVIII.

RolNIK, S. Florações da realidade. Núcleo de Estudos da Subjetividade, São Paulo. p. 1-12, maio, n. 77 dez. 2020. Disponível em: <https://www.pucsp.br/nucleodesubjetividade/suely\%20rolnik.htm>. Acesso em: 28, jul. 2021.

UNIQUe ONE. Página oficial do projeto The Burned Picasso. Disponível em: <https://uniqueone.medium.com/picasso-entersthe-metaverse-f1cc48c77ed8 > Acesso em: 29, jul. 2021.

Vergara, C. Perfil do Ateliê Carlos Vergara no Instagram. Disponível em:

<https://www.instagram.com/ateliecarlosvergara/>. Acesso em: 29, jul. 2021.

XAVIER, I. O discurso cinematográfico: opacidade e transparência. São Paulo: Paz e Terra, 2005.

Recebido em: 30/07/2021

Aceito em: 06/10/2021 